\title{
On the Dynamic Analysis of a Beam Carrying Multiple Mass-Spring-Mass-Damper System
}

\author{
O. Barry, ${ }^{1}$ D. C. D. Oguamanam, ${ }^{2}$ and J. W. Zu ${ }^{1}$ \\ ${ }^{1}$ Department of Mechanical and Industrial Engineering, University of Toronto, Toronto, ON, Canada M5S $3 G 8$ \\ ${ }^{2}$ Department of Mechanical and Industrial Engineering, Ryerson University, Toronto, ON, Canada M5B 2K3 \\ Correspondence should be addressed to O. Barry; rafioulabe@gmail.com
}

Received 25 July 2013; Accepted 6 October 2013; Published 23 February 2014

Academic Editor: Jeong-Hoi Koo

Copyright (c) 2014 O. Barry et al. This is an open access article distributed under the Creative Commons Attribution License, which permits unrestricted use, distribution, and reproduction in any medium, provided the original work is properly cited.

\begin{abstract}
The exact natural frequencies, mode shapes, and the corresponding orthogonality relations are important in forced vibration analysis via modal expansion. In the present paper, a free vibration analysis is conducted to determine the exact natural frequencies and mode shapes of an axially loaded beam carrying several absorbers. An explicit expression is presented for the generalized orthogonality relations. These generalized orthogonality conditions are employed along with the assumed modes method to perform forced vibration analysis. The present approach is compared to other approximate methods in the literature with the classical orthogonality relations and different choice of mode shapes. The results indicate that the use of the generalized orthogonality relation with the exact mode shapes is required for a precise investigation of the dynamic response of a beam with mass-spring-mass-damper system.
\end{abstract}

\section{Introduction}

The study of beam vibrations is attracting continued interest all these years because of the wide range of engineering applications involving beams. Beam models are used to idealize buildings components, bridges, overhead transmission lines, microelectromechanical systems, and many more. In the case of overhead transmission lines a single conductor may be modeled as a beam that is subjected to a tensile load with the damper represented as a mass-spring-damper-mass system.

Numerous authors have studied the free and/or forced response of beams carrying in-span mass or spring-mass systems. In most investigations on the free vibration, different authors have used analytical methods to determine the exact solutions for the natural frequencies and mode shapes (e.g., [1-13] and references mentioned therein).

There are, however, few published exact solutions of the forced vibration problems. The most common analytical approach used in forced vibration analysis is based on the assumed modes method in conjunction with the classical orthogonality conditions which may be expressed as $\int_{0}^{L} Y_{i} Y_{j} d x=\delta_{i j}$, where $L$ is the length of the beam, $Y_{i}$ and $Y_{j}$ are the $i$ th and $j$ th normal mode shapes, respectively, and $\delta_{i j}$ is the Kronecker delta function. Hereinafter a beam without mass or spring-mass system is referred to as a bare beam, or else it is called a loaded beam.

In [14-16], the authors employed the mode shapes of the bare beam and the classical orthogonality condition to study the forced response of loaded beams. Combinations of the mode shapes of the loaded beam with the classical orthogonality relation were employed in [17-23]. These two approaches are simple and easy to implement and, in some cases, give very good approximations. However, it was shown in $[21,24]$ that the mode shapes of the loaded beam and those of the bare beam are different. Further, Hassanpour et al. [25] showed that the mode shapes of the loaded beam were not orthonormal under the classical orthogonality conditions. They also presented the generalized orthogonality conditions for an axially loaded beam with in-span concentrated mass and springs. The study ignored the case where a suspended mass is connected to the beam via a spring-dashpot system.

The majority of the studies reported in the literature focused on the study of beams with either an in-span mass or spring-mass system. A series combination of each type 
was found in some cases. However, works that simultaneously examined the free and forced vibration of a beam with multiple in-span mass-spring-damper-mass systems and subjected to an axial force were not found. The investigation of this problem is reported in the present paper; it is an extension of the work presented in [13]. The exact natural frequencies and mode shapes are determined and explicit expressions are presented for the orthogonality relations. Parametric studies are used to examine the effect of the magnitude and location of the in-span mass-spring-damper-mass system on the natural frequencies and vibrational response. The effect of the use of the classical orthogonality condition is also examined. The results are validated using the finite element method and results from the literature.

\section{Equations of Motion}

A schematic of a beam with several in-span mass-springdamper-mass systems is depicted in Figure 1. The system kinetic energy $\mathscr{T}$ and potential energy $\mathscr{V}$ may be expressed as

$$
\begin{array}{r}
\mathscr{T}=\sum_{i=1}^{N}\left(\frac{1}{2} m \int_{L_{i-1}}^{L_{i}} \dot{w}_{i}^{2}(x, t) d x+\frac{1}{2} M_{d i} \dot{z}_{i}^{2}+\frac{1}{2} M_{c i} \dot{z}_{0 i}^{2}\right), \\
\mathscr{V}=\sum_{i=1}^{N}\left(\frac{1}{2} E I \int_{L_{i-1}}^{L_{i}} w_{i}^{\prime \prime 2}(x, t) d x+\frac{1}{2} c_{d i}\left(\dot{z}_{0 i}-\dot{z}_{i}\right)^{2}\right. \\
\left.+\frac{1}{2} k_{i}\left(z_{0 i}-z_{i}\right)^{2}+\frac{1}{2} T \int_{L_{i-1}}^{L_{i}} w_{i}^{\prime 2}(x, t) d x\right),
\end{array}
$$

where $z_{0 i}(t)=w_{i}\left(L_{i}, t\right), E I$ is the beam flexural rigidity, $m$ is the mass per unit length of the beam, and $T$ is the beam pretension. The overdots and primes denote temporal and spatial derivatives, respectively. The subscript " $i$ " denotes the position of the mass-spring-damper-mass system and " $N$ " is the total number of attached mass-spring-damper-mass systems. The beam is assumed to be uniform and the pretension is constant.

Introducing these energies equations into Hamilton's principle and adding the forcing term $F(x, t)$ yield the equations of motion and continuity conditions:

$$
\begin{gathered}
E I w_{i}^{\prime \prime \prime \prime}+m \ddot{w}_{i}-T w_{i}^{\prime \prime}=F(x, t) \\
M_{d i} \ddot{z}+k_{i}\left(z_{i}-z_{0 i}\right)+c_{d i}\left(\dot{z}_{i}-\dot{z}_{0 i}\right)=0 \\
w_{i}\left(L_{i}, t\right)=w_{i+1}\left(L_{i}, t\right) \\
w_{i}^{\prime}\left(L_{i}, t\right)=w_{i+1}^{\prime}\left(L_{i}, t\right) \\
w_{i}^{\prime \prime}\left(L_{i}, t\right)=w_{i+1}^{\prime \prime}\left(L_{i}, t\right)-M_{c i} \ddot{z}_{0 i}+E I w_{i}^{\prime \prime \prime}\left(L_{i}, t\right) \\
-T w_{i}^{\prime}\left(L_{i}, t\right)-k_{i}\left(z_{0 i}-z_{i}\right)-c_{d i}\left(\dot{z}_{0 i}-\dot{z}_{i}\right) \\
-E I w_{i+1}^{\prime \prime \prime}\left(L_{i}, t\right)+T w_{i+1}^{\prime}\left(L_{i}, t\right)=0
\end{gathered}
$$

\section{Frequency Equation and Mode Shapes}

The deformations $w_{i}\left(x_{i}, t\right)$ and displacements $z(t)$ are expressed as

$$
\begin{gathered}
w_{i}\left(x_{i}, t\right)=L W_{i}(\zeta) \mathrm{e}^{\omega t}, \\
z_{i}(t)=L A_{i} \mathrm{e}^{\omega t},
\end{gathered}
$$

where $W_{i}\left(\zeta_{i}\right)$ and $A_{i}$ are the respective nondimensional amplitudes of $w_{i}\left(x_{i}, t\right)$ and $z_{i}(t)$ and $\omega$ is the circular complex natural frequency of the system. Substituting (8) into (2)-(7) yields the following nondimensional system equations:

$$
\begin{gathered}
W_{i}^{\prime \prime \prime \prime}\left(\zeta_{i}\right)-s^{2} W_{i}^{\prime \prime}\left(\zeta_{i}\right)+\Omega^{4} W_{i} \zeta_{i}=0, \\
A_{i}-K_{i} W_{i}\left(\xi_{i}\right)=0,
\end{gathered}
$$

where

$$
W_{i}\left(\zeta_{i}\right)=c_{1 i} \sin \alpha \zeta_{i}+c_{2 i} \cos \alpha \zeta_{i}+c_{3 i} \sinh \beta \zeta_{i}+c_{4 i} \cosh \beta \zeta_{i} .
$$

Substituting (8) into (3)-(7) yields

$$
\begin{gathered}
W_{i}\left(\xi_{i}\right)=W_{i+1}\left(\xi_{i}\right), \\
W_{i}^{\prime}\left(\xi_{i}\right)=W_{i+1}^{\prime}\left(\xi_{i}\right), \\
W_{i}^{\prime \prime}\left(\xi_{i}\right)=W_{i+1}^{\prime \prime}\left(\xi_{i}\right), \\
W_{i}^{\prime \prime \prime}\left(\xi_{i}\right)-W_{i+1}^{\prime \prime \prime}\left(\xi_{i}\right)-\eta_{i} W_{i}\left(\xi_{i}\right)+\gamma_{i} A_{i}=0,
\end{gathered}
$$

where the following nondimensional variables are used:

$$
\begin{gathered}
\xi_{i}=\frac{L_{i}}{L}, \quad A_{i}=K W_{i}\left(\xi_{i}\right), \\
K_{i}=\frac{k_{i}+\omega c_{d i}}{k_{i}+M_{d i} \omega^{2}+\omega c_{d i}}, \quad s^{2}=\frac{T L^{2}}{E I}, \\
\Omega^{4}=\frac{m \omega^{2}}{E I} L^{4}, \quad \eta_{i}=\frac{k_{i}+\omega^{2} M_{c i}+\omega c_{d i}}{E I} L^{3}, \\
\alpha=\sqrt{-\frac{s_{i}^{2}}{2}+\sqrt{\frac{s^{4}}{4}+\Omega_{d i}}}, \quad \beta=\frac{x}{L}, \quad L^{3}, \quad \frac{s}{2}^{2}+\sqrt{\frac{s^{4}}{4}+\Omega^{4}} .
\end{gathered}
$$

Substituting (10) into (15) yields

$$
W_{i}^{\prime \prime \prime}\left(\xi_{i}\right)-W_{i}^{\prime \prime \prime}\left(\xi_{i}\right)+W_{i}\left(\xi_{i}\right)\left(K_{i} \gamma_{i}-\eta_{i}\right)=0 .
$$

The use of any classical boundary conditions at each end of the beam along with (12)-(14) and (17) yields a set of $4+$ $4 \mathrm{~N}$ algebraic homogeneous equations (4 equations from the boundary condition at the ends and $4 N$ equations from the continuity relations). These algebraic equations are linear in the unknown coefficients ( $C$ 's) and they can be presented in matrix format as

$$
[\mathscr{F}]_{(4+4 N) X(4+4 N)}\{C\}_{(4+4 N) X(1)}=\{0\}_{(4+4 N) X(1)},
$$




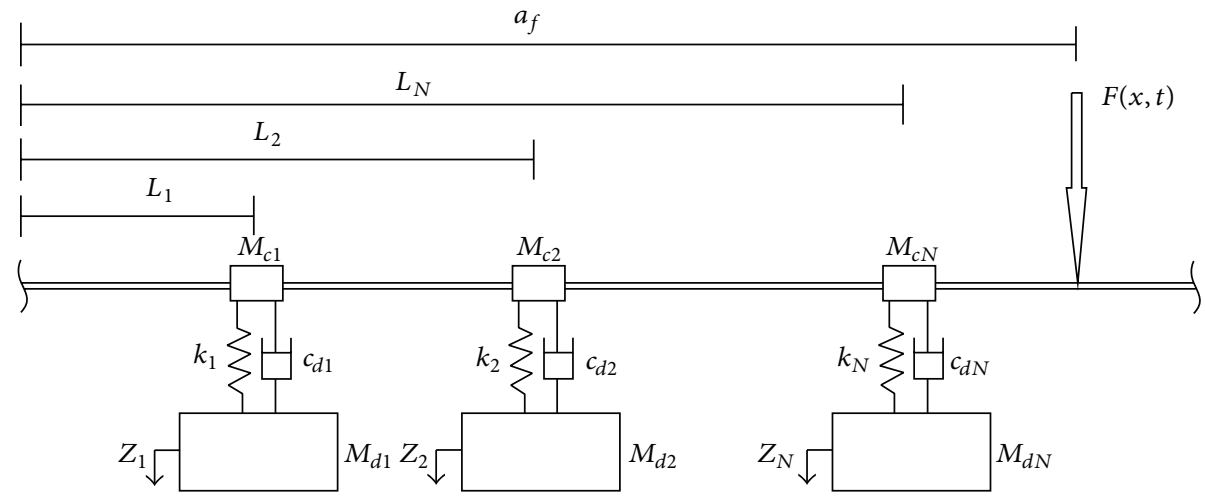

FIGURE 1: Schematic of an axial beam carrying several mass-spring-damper-mass systems.

where the elements of the matrix $\mathscr{F}$ are listed in the Appendix. A nontrivial solution is obtained when matrix $\mathscr{F}$ is singular. Hence, the characteristic or frequency equation is obtained as

$$
\operatorname{det}\left([\mathscr{F}]_{(4+4 N) X(4+4 N)}\right)=0 .
$$

The mode shapes associated with each beam segment are obtained by substituting the integration constants from (18) into (11). An example of a matrix that yields the frequency equation is provided in the Appendix for the case of a cantilever beam with one in-span mass-spring-damper-mass support.

\section{Generalized Orthogonality Relations}

The solution of the equations of motion, (2) and (3), can be expressed as

$$
\begin{aligned}
w_{i}(x, t) & =Y_{i}(x)^{(r)} \mathrm{e}^{\omega t}, \\
z_{i}(t) & =Z_{i}^{(r)} \mathrm{e}^{\omega t},
\end{aligned}
$$

where the superscript " $r$ " denotes the mode number and

$$
\begin{aligned}
Y_{i}(x) & =L W_{i}(\zeta), \\
Z_{i} & =L A_{i} .
\end{aligned}
$$

Substituting (20) into (3) and multiplying the resulting equation by $Z^{(s)}$ yield

$$
\begin{aligned}
& k_{i} Z_{i}^{(r)} Z_{i}^{(s)}+M_{d i} \omega_{r}^{2} Z_{i}^{(r)} Z_{i}^{(s)}+\omega_{r} c_{d i} Z_{i}^{(r)} Z_{i}^{(s)} \\
& =Y_{i}^{*(r)} Z_{i}^{(s)}\left(k_{i}+\omega_{r} c_{d i}\right),
\end{aligned}
$$

where $Y_{i}^{*(r)}=Y_{i}^{(r)}\left(\xi_{1}\right)$, Interchanging " $r$ " and " $s$ " in (22) and subtracting the resulting equation from (22) yield

$$
\begin{aligned}
\left(\omega_{r}^{2}-\omega_{s}^{2}\right) M_{d i} Z_{i}^{(r)} Z_{i}^{(s)}+c_{d i}\left(\omega_{r}-\omega_{s}\right) Z_{i}^{(r)} Z_{i}^{(s)} \\
=k_{i}\left(Y_{i}^{*(r)} Z_{i}^{(s)}-Y_{i}^{*(s)} Z_{i}^{(r)}\right) \\
\quad+c_{d i}\left(\omega_{r} Y_{i}^{*(r)} Z_{i}^{(s)}-\omega_{s} Y_{i}^{*(s)} Z_{i}^{(r)}\right) .
\end{aligned}
$$

With reference to the equations of motion of the beam, substituting (20) into (2), then multiplying the resulting equation by $Y^{(s)}$, and integrating over the entire length of the beam, as well as applying the continuity conditions, (12)-(15), with any classical boundary conditions except those for free ends yield

$$
\begin{aligned}
\omega_{r}^{2} \sum_{i=1}^{N}\left(m \int_{0}^{L_{i}} Y_{i}^{(r)} Y_{i}^{(s)} d x+M_{c i} Y_{i}^{*(r)} Y_{i}^{*(s)}\right) \\
+\omega_{r} \sum_{i=1}^{N} c_{d i} Y_{i}^{*(r)} Y_{i}^{*(s)} \\
=-\sum_{i=1}^{N}\left(E I \int_{0}^{L_{i}} Y_{i}^{\prime \prime(r)} Y_{i}^{\prime \prime(s)} d x\right. \\
+T \int_{0}^{L_{i}} Y_{i}^{\prime(r)} Y_{i}^{\prime(s)} d x+k_{i} Y_{i}^{*(r)} Y_{i}^{*(s)} \\
\left.\quad-k_{i} Z_{i}^{(r)} Y_{i}^{*(s)}-c_{d i} \omega_{r} Z_{i}^{(r)} Y_{i}^{*(s)}\right) .
\end{aligned}
$$

Rewriting (24) and interchanging " $r$ " and " $s$ " yield

$$
\begin{gathered}
\omega_{s}^{2} \sum_{i=1}^{N}\left(m \int_{0}^{L_{i}} Y_{i}^{(s)} Y_{i}^{(r)} d x+M_{c i} Y_{i}^{*(s)} Y_{i}^{*(r)}\right)+\omega_{s} \sum_{i=1}^{N} c_{d i} Y_{i}^{*(s)} Y_{i}^{*(r)} \\
=-\sum_{i=1}^{N}\left(E I \int_{0}^{L_{i}} Y_{i}^{\prime \prime(s)} Y_{i}^{\prime \prime(r)} d x\right. \\
+T \int_{0}^{L_{i}} Y_{i}^{\prime(s)} Y_{i}^{\prime(r)} d x+k_{i} Y_{i}^{*(r)} Y_{i}^{*(s)} \\
\left.-k_{i} Z_{i}^{(s)} Y_{i}^{*(r)}-c_{d i} \omega_{s} Z_{i}^{(s)} Y_{i}^{*(r)}\right) .
\end{gathered}
$$

Subtracting (25) from (24) and substituting (23) into the resulting equation yield

$$
\begin{gathered}
\left(\omega_{r}^{2}-\omega_{s}^{2}\right) \sum_{i=1}^{N}\left(m \int_{0}^{L_{i}} Y_{i}^{(r)} Y_{i}^{(s)} d x+M_{c i} Y_{i}^{*(r)} Y_{i}^{*(s)}\right. \\
\left.+M_{d i} Z_{i}^{(r)} Z_{i}^{(s)}\right) \\
+\left(\omega_{r}-\omega_{s}\right) \sum_{i=1}^{N} c_{d i}\left(Y_{i}^{*(r)} Y_{i}^{*(s)}+Z_{i}^{(r)} Z_{i}^{(s)}\right)=0 .
\end{gathered}
$$


From (26), the first set of orthogonality relation is obtained as

$$
\sum_{i=1}^{N}\left(m \int_{0}^{L_{i}} Y_{i}^{(r)} Y_{i}^{(s)} d x+M_{c i} Y_{i}^{*(r)} Y_{i}^{*(s)}+M_{d i} Z_{i}^{(r)} Z_{i}^{(s)}\right)=\delta_{r s}
$$

where $\delta_{r s}$ is the Kronecker delta. The second set of orthogonality relation is expressed as

$$
\sum_{i=1}^{N}\left(Y_{i}^{*(r)} Y_{i}^{*(s)}+Z_{i}^{(r)} Z_{i}^{(s)}\right)=\delta_{r s}
$$

The use of (22) and (25) with the aid of some algebraic manipulation yields the third and fourth set of orthogonality relation. This may be written as

$$
\begin{aligned}
& \sum_{i=1}^{N}\left(E I \int_{0}^{L_{i}} Y_{i}^{\prime \prime(r)} Y_{i}^{\prime \prime(s)} d x+T \int_{0}^{L_{i}} Y_{i}^{\prime(r)} Y_{i}^{\prime(s)} d x\right) \\
& \quad+\sum_{i=1}^{N} k_{i}\left(Y_{i}^{*(r)} Y_{i}^{*(s)}-Z_{i}^{(s)} Y_{i}^{*(r)}-Z_{i}^{(r)} Y_{i}^{*(s)}+Z_{i}^{(r)} Z_{i}^{(s)}\right) \\
& =\delta_{r s}, \\
& \quad \sum_{i=1}^{N}\left(Y_{i}^{*(r)} Z_{i}^{*(s)}+Z_{i}^{(r)} Y_{i}^{(s)}\right)=\delta_{r s}
\end{aligned}
$$

\section{Forced Vibration}

Assume a harmonic force $F(x, t)$ is arbitrarily applied along the span of the beam as depicted in Figure 1. The response of the loaded beam is now derived using the generalized orthogonality relations (27)-(30). Let the excitation force be applied at a location $a_{f}$ from the left-hand end on the beam; the governing equations of motion are now

$$
\begin{array}{r}
m \ddot{w}_{i}+E I w_{i}^{\prime \prime \prime \prime}-T w_{i}^{\prime \prime}=F(x, t) \delta\left(x-a_{f}\right), \\
M_{d i} \ddot{z}_{i}+k_{i}\left(z_{i}-w_{i}\left(L_{i}\right)\right)+c_{d i}\left(\dot{z}_{i}-\dot{w}_{i}\left(L_{i}\right)\right)=0 .
\end{array}
$$

Using the assumed mode method, the transverse displacement of the beam and the displacement of vibration absorber may be expressed as

$$
\begin{gathered}
w_{i}=\sum_{r=1}^{N_{r}} q_{r}(t) Y_{i}^{(r)}(x), \\
z_{i}=\sum_{r=1}^{N_{r}} q_{r}(t) Z_{i}^{(r)},
\end{gathered}
$$

where $N_{r}$ is the number of retained modes, $Y_{i}^{(r)}(x)$ is the mode shape corresponding to the $r$ th mode, $Z_{i}^{(r)}$ is the displacement amplitude of the absorber, and $q_{r}(t)$ is the $r$ th generalized coordinate. Substituting (33) and (34) into (31) and (32), respectively, yields

$$
\begin{gathered}
m_{c} \sum_{r=1}^{N_{r}} \ddot{q}_{r} Y_{i}^{(r)}+E I \sum_{r=1}^{N_{r}} q_{r} Y_{i}^{\prime \prime \prime \prime(r)}-T \sum_{r=1}^{N_{r}} q_{r} Y_{i}^{\prime \prime(r)}, \\
=F(t) \delta\left(x-a_{f}\right) \\
M_{d i} \sum_{r=1}^{N_{r}} \ddot{q}_{r} Y_{m i}^{(r)}+k_{i} \sum_{r=1}^{N_{r}} q_{r}\left(Z_{i}^{(r)}-Y_{c i}^{(r)}\left(L_{i}\right)\right) \\
\quad+c_{d i} \sum_{r=1}^{N_{r}} \dot{q}_{r}\left(Z_{i}^{(r)}-Y_{c i}^{(r)}\left(L_{i}\right)\right)=0 .
\end{gathered}
$$

Multiplying (35) by $Y_{i}^{(s)}$ and $Z_{i}^{(s)}$, respectively, adding the two resulting equations, integrating over the entire length of the beam, and applying the continuity conditions, (12)-(15), with any classical boundary conditions (except for free ends) yield

$$
\begin{aligned}
& \sum_{r=1}^{N_{r}} \ddot{q}_{r}\left\{m \int_{0}^{L_{i}} Y_{i}^{(r)} Y_{i}^{(s)} d x+M_{c i} Y_{i}^{*(r)} Y_{i}^{*(s)}+M_{d i} Z_{i}^{(r)} Z_{i}^{(s)}\right\} \\
& +c_{d i} \sum_{r=1}^{N_{r}} \dot{q}_{r}\left\{Y_{i}^{*(r)} Y_{i}^{*(s)}-Z_{i}^{(s)} Y_{i}^{*(r)}-Z_{i}^{(r)} Y_{i}^{*(s)}+Z_{i}^{(r)} Z_{i}^{(s)}\right\} \\
& +\sum_{r=1}^{N_{r}} q_{r}\left\{\int_{0}^{L_{i}}\left(E I Y_{i}^{\prime \prime(r)} Y_{i}^{\prime \prime(s)}+T Y_{i}^{\prime(r)} Y_{i}^{\prime(s)}\right) d x\right. \\
& \quad+k_{i}\left(Y_{i}^{*(r)} Y_{i}^{*(s)}-Z_{i}^{(s)} Y_{i}^{*(r)}\right. \\
& \left.\left.\quad-Z_{i}^{(r)} Y_{i}^{*(s)}+Z_{i}^{(r)} Z_{i}^{(s)}\right)\right\} \\
& =F(x, t) Y_{i}^{(s)}\left(a_{f}\right) .
\end{aligned}
$$

Use of the orthogonality relations, (27)-(30), yields the following uncoupled differential equation:

$$
\left[M_{r r}\right]\left\{\ddot{q}_{r}\right\}+\left[C_{r r}\right]\left\{\dot{q}_{r}\right\}+\left[K_{r r}\right]\left\{q_{r}\right\}=\left\{F_{r}\right\},
$$

where the matrices $M_{r r}, C_{r}$, and $K_{r r}$ are expressed as

$$
\begin{gathered}
M_{r r}=\sum_{i=1}^{N}\left(m \int_{0}^{L_{i}} Y_{i}^{(r)^{2}} d x+M_{c i} Y_{i}^{*(r)^{2}}+M_{d i} Z_{i}^{(r)^{2}}\right), \\
C_{r r}=\sum_{i=1}^{N} c_{d i}\left(Y_{i}^{*(r)}-Z_{i}^{(r)}\right)^{2} \\
K_{r}=\sum_{i=1}^{N}\left\{\int_{0}^{L_{i}}\left(E I Y_{i}^{\prime \prime(r)^{2}}+T Y_{i}^{\prime(r)^{2}}\right) d x+k_{i}\left(Y_{i}^{*(r)}-Z_{i}^{(r)}\right)^{2}\right\} \\
F_{r}=F(x, t) Y_{i}^{(r)}\left(a_{f}\right) .
\end{gathered}
$$


TABLE 1: Material properties and parameters.

\begin{tabular}{lccc}
\hline Parameter & Reference [1] & Reference [16] & Units \\
\hline$E I$ & 63476.1 & 36.4583 & $\mathrm{Nm}^{2}$ \\
$L$ & 1.0 & 1.0 & $\mathrm{~m}$ \\
$m$ & 15.385 & 0.675 & $\mathrm{~kg} / \mathrm{m}$ \\
$m_{1}$ & 3.0775 & 0.1 & $\mathrm{~kg}$ \\
$m_{2}$ & 4.614 & 0.1 & $\mathrm{~kg}$ \\
$m_{3}$ & 7.69 & 0.1 & $\mathrm{~kg}$ \\
$m_{4}$ & 9.997 & - & $\mathrm{kg}$ \\
$m_{5}$ & 15.38 & - & $\mathrm{kg}$ \\
$k_{1}$ & 190428 & 0.1 & $\mathrm{~N} / \mathrm{m}$ \\
$k_{2}$ & 222166 & 0.1 & $\mathrm{~N} / \mathrm{m}$ \\
$k_{3}$ & 285642.45 & 0.1 & $\mathrm{~N} / \mathrm{m}$ \\
$k_{4}$ & 317380 & - & $\mathrm{N} / \mathrm{m}$ \\
$k_{5}$ & 380856 & - & $\mathrm{N} / \mathrm{m}$ \\
$c_{d 1}, c_{d 2}, c_{d 3}$ & - & 0.1 & $\mathrm{Ns} / \mathrm{m}$ \\
\hline
\end{tabular}

The amplitude of the vibration absorber can be readily expressed as

$$
\begin{gathered}
Z_{i}^{(r)}=\kappa_{i} Y_{i}^{*(r)}, \\
\kappa_{i}=\left(\frac{1+\left(2 \varsigma_{i} r_{i}\right)^{2}}{\left(1-r_{i}^{2}\right)^{2}+\left(2 \varsigma_{i} r_{i}\right)^{2}}\right)^{1 / 2}, \quad \varsigma_{i}=\frac{c_{d i}}{2 M_{d i} \omega_{s i}}, \\
r_{i}=\frac{\Omega}{\omega_{s i}}, \quad \omega_{s i}=\sqrt{\frac{k_{i}}{M_{d i}}} .
\end{gathered}
$$

\section{Numerical Simulation}

The sets of parameters employed in the numerical examples are taken from $[1,16]$; they are tabulated in Table 1 . The validity of the free vibration of the present model is inferred from the results tabulated in Table 2. In the case of a cantilevered beam with three spring-mass-damper systems, the first five natural frequencies of the present model are compared to those of [16]. The results show very good agreement with a maximum error of $0.28 \%$.

With respect to a pinned-pinned beam with attached three and five spring-mass systems, the validation is done via [1] and shows excellent agreement with four decimal places. The corresponding mode shapes for a beam carrying the three in-span spring-mass systems are depicted in Figure 2. This figure is identical to Figure 3 from [1].

For the forced vibration simulations, an excitation force of $F(t)=10 \sin (\Omega t)$ is used with zero initial conditions. The force is first applied at the free end of a cantilevered beam with three identical spring-mass-damper systems located at $0.1,0.5$, and $0.9 \mathrm{~m}$ from the clamp end. The time history of the vertical displacement of the free end is presented to serve for comparison between the proposed approach (i.e., the combination of the generalized orthogonality conditions with the exact mode shapes of the loaded beam), the finite element method (FEM), and the approach used in [16]. The results are depicted in Figures 3 and 4 for an excitation frequency of 5 and $10 \mathrm{rad} / \mathrm{s}$, respectively. All three methods are in agreement,

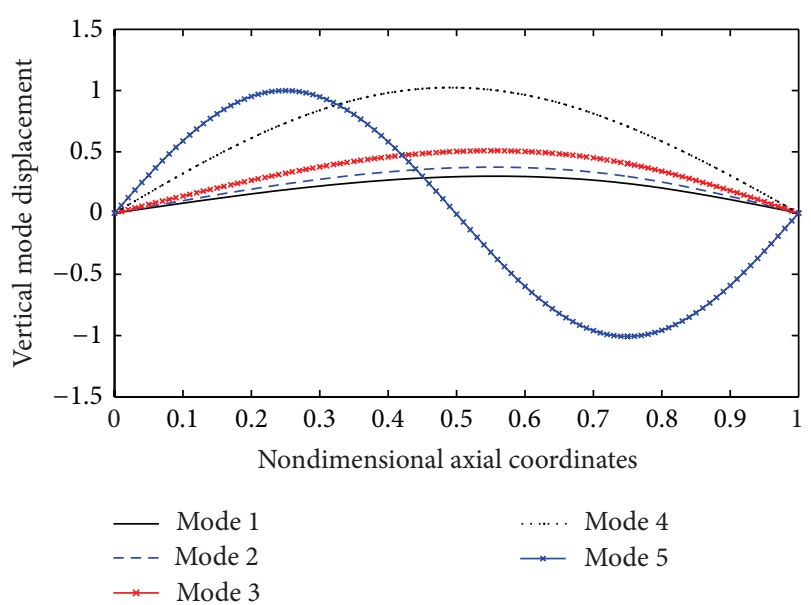

FIGURE 2: Mode shapes of a simply supported beam carrying three in-span spring-mass systems using the same parameters from [1].

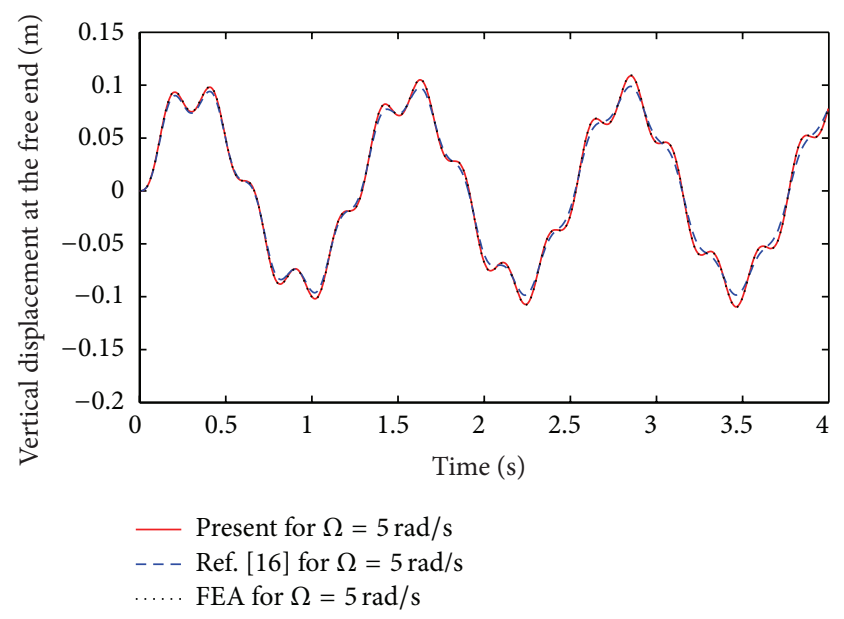

FIGURE 3: Time history of the free-end vertical displacement for a cantilevered beam carrying three mass-spring-damper systems for a forcing frequency $\Omega=5 \mathrm{rad} / \mathrm{s}, k=0.1 \mathrm{~N} / \mathrm{m}, T=0, M_{d}=0.1 \mathrm{~kg}$, $M_{c}=0 \mathrm{~kg}, c_{d}=0.1 \mathrm{Ns} / \mathrm{m}$, and $L_{1 ; 2 ; 3}=0.1,0.5,0.9 \mathrm{~m}$.

but the FEM results agree better with the present approach than that of [16].

The frequency response curves for a simply supported beam with one in-span mass-spring-damper-mass system attached at $0.1 \mathrm{~m}$ from one end using three approaches are depicted in Figure 5. The first approach, which is the most accurate [25], employs the generalized orthogonality conditions along with the mode shapes of the loaded beam. The classical orthogonality relations and the mode shapes of the loaded beam are employed in the second approach, such as in [17-20]. The third method also uses the classical orthogonality conditions, but the mode shapes are those of the bare beam (see [14-16]). All three approaches yield very different midspan vertical displacements. The first approach is the exact solution and hence the error associated with the difference is defined with respect to the first approach. The frequency response amplitude errors are depicted in Figure 6 where the error can be as high as $10^{4}$. 
TABLE 2: Natural frequency validation ( $\mathrm{rad} / \mathrm{s})$.

\begin{tabular}{|c|c|c|c|c|c|c|}
\hline \multirow{3}{*}{ Mode } & \multirow{2}{*}{\multicolumn{2}{|c|}{$\begin{array}{c}\text { Cantilevered } \\
3 \text { spring-mass-damper }\end{array}$}} & \multicolumn{4}{|c|}{ Pinned-pinned } \\
\hline & & & \multicolumn{2}{|c|}{3 spring-mass } & \multicolumn{2}{|c|}{5 spring-mass } \\
\hline & Reference [16] & Present & Reference [1] & Present & Reference [1] & Present \\
\hline 1 & $-0.367 \pm 25.8769 i$ & $-0.367 \pm 25.8544 i$ & 152.7339 & 152.7339 & 150.9571 & 150.9571 \\
\hline 2 & $-0.274 \pm 161.7655 i$ & $-0.275 \pm 161.9399 i$ & 185.0949 & 185.0949 & 169.4728 & 169.4728 \\
\hline 3 & $-0.031 \pm 452.1367 i$ & $-0.031 \pm 452.4320 i$ & 247.8313 & 247.8313 & 187.9146 & 187.9146 \\
\hline 4 & $-0.171 \pm 887.2157 i$ & $-0.174 \pm 887.3469 i$ & 677.5959 & 677.5959 & 217.1278 & 217.1278 \\
\hline 5 & $-0.081 \pm 1467.5170 i$ & $-0.082 \pm 1468.8356 i$ & 2548.6572 & 2548.6572 & 247.9867 & 247.9867 \\
\hline
\end{tabular}

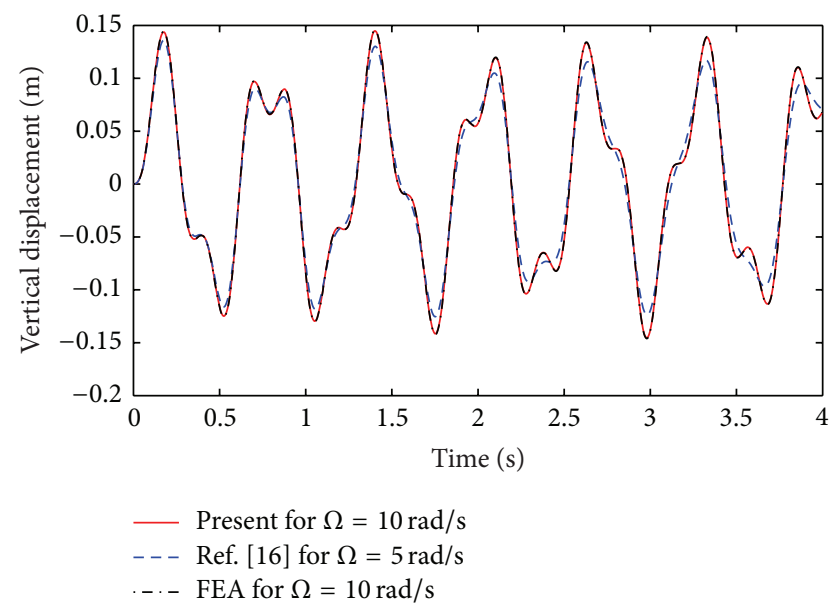

FIGURE 4: Time history of the free-end vertical displacement for a cantilevered beam carrying three mass-spring-damper systems for a forcing frequency $\Omega=10 \mathrm{rad} / \mathrm{s}, k=0.1 \mathrm{~N} / \mathrm{m}, T=0, M_{d}=0.1 \mathrm{~kg}$, $M_{c}=0 \mathrm{~kg}, c_{d}=0.1 \mathrm{Ns} / \mathrm{m}$, and $L_{1 ; 2 ; 3}=0.1,0.5,0.9 \mathrm{~m}$.

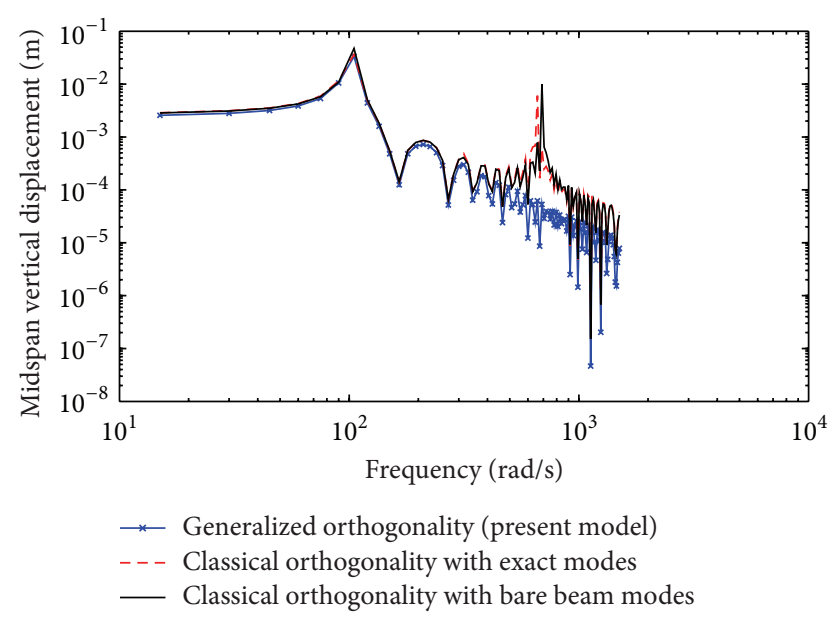

FIGURE 5: Frequency response of a simply supported beam carrying one in-span mass-spring-damper-mass system for $k=10 \mathrm{~N} / \mathrm{m}$, $M_{d}=0.1 \mathrm{~kg}, M_{c}=0.05 \mathrm{~kg}, T=360 \mathrm{~N}, E I=36.458 \mathrm{Nm}^{2}, c_{d}=$ $0.1 \mathrm{Ns} / \mathrm{m}$, and $L_{d}=0.1 \mathrm{~m}$.

Figure 7 is an identical plot to Figure 5 with the pinnedpinned configuration replaced by a guided-guided one. The corresponding frequency response amplitude error is shown

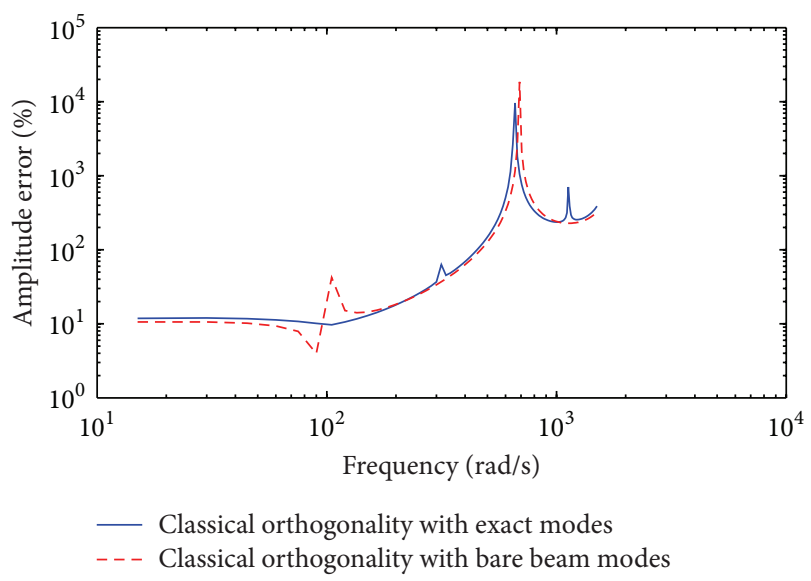

FIGURE 6: Frequency response amplitude error for a simply supported beam carrying one in-span mass-spring-damper-mass system for $k=10 \mathrm{~N} / \mathrm{m}, M_{d}=0.1 \mathrm{~kg}, M_{c}=0.05 \mathrm{~kg}, T=360 \mathrm{~N}$, $E I=36.458 \mathrm{Nm}^{2}, c_{d}=0.1 \mathrm{Ns} / \mathrm{m}$, and $L_{d}=0.1 \mathrm{~m}$.

in Figure 8. The maximum amplitude error for the guidedguided beam is higher than that for the simply supported beam. A similar observation with regard to the discrepancy associated with the use of the classical orthogonality was reported in [25] for a simply supported beam carrying a heavy mass. An error as high as $10^{5}$ was reported.

The three approaches are also examined using the parameters taken from [1] for a simply supported beam with one in-span mass-spring-damper system and no tension. Figures 9 and 10 show the frequency response of the midspan displacement for a damping coefficient $c_{d i}=0.1 \mathrm{Ns} / \mathrm{m}$ and $c_{d i}=100 \mathrm{Ns} / \mathrm{m}$, respectively. It can be observed that all three methods yield very similar results and the plots are barely distinguishable. The amplitude errors associated with the results presented in Figures 9 and 10 are depicted in Figures 11 and 12, respectively. But for excitation frequencies closer to $600 \mathrm{rad} / \mathrm{s}$ the results indicate very minimal error. The discrepancy is more pronounced in the case of the classical orthogonality with the combination of the bare beam mode shapes.

\section{Conclusions}

A common approach to studying the vibrational response of an elastically loaded beam involves the use of the classical 


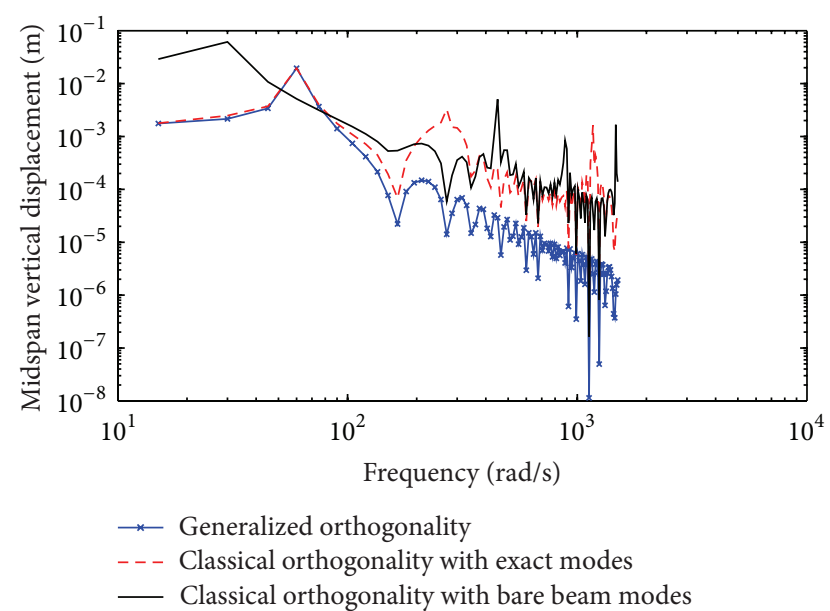

FIGURE 7: Frequency response of a guided-guided beam carrying one in-span mass-spring-damper-mass system for $k=10 \mathrm{~N} / \mathrm{m}$, $M_{d}=0.1 \mathrm{~kg}, M_{c}=0.05 \mathrm{~kg}, T=360 \mathrm{~N}, E I=36.458 \mathrm{Nm}^{2}$, $c_{d}=0.1 \mathrm{Ns} / \mathrm{m}$, and $L_{d}=0.1 \mathrm{~m}$.

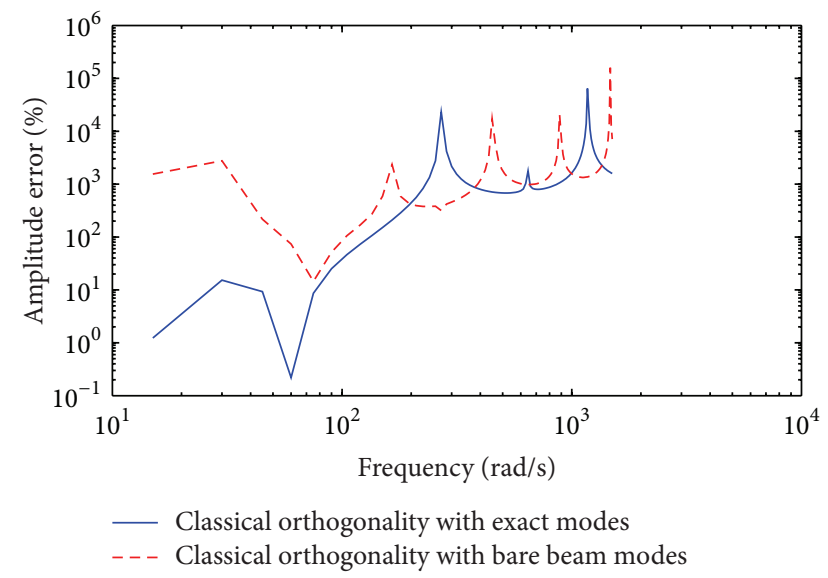

FIGURE 8: Frequency response amplitude error of a guided-guided beam carrying one in-span mass-spring-damper-mass system for $k=10 \mathrm{~N} / \mathrm{m}, M_{d}=0.1 \mathrm{~kg}, M_{c}=0.05 \mathrm{~kg}, T=360 \mathrm{~N}, E I=$ $36.458 \mathrm{Nm}^{2}, c_{d}=0.1 \mathrm{Ns} / \mathrm{m}$, and $L_{d}=0.1 \mathrm{~m}$.

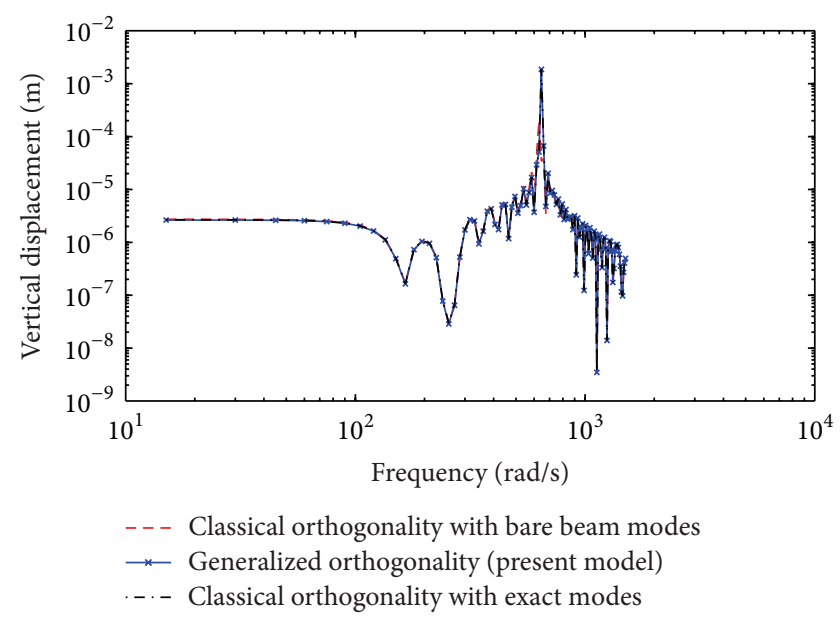

FIGURE 9: Frequency response of a simply supported beam carrying one in-span mass-spring-damper-mass system for $k=190428 \mathrm{~N} / \mathrm{m}$, $M_{d}=3.0775 \mathrm{~kg}, M_{c}=0 \mathrm{~kg}, T=0 \mathrm{~N}, E I=63476.1 \mathrm{Nm}^{2}, c_{d}=$ $0.1 \mathrm{Ns} / \mathrm{m}$, and $L_{d}=0.75 \mathrm{~m}$.

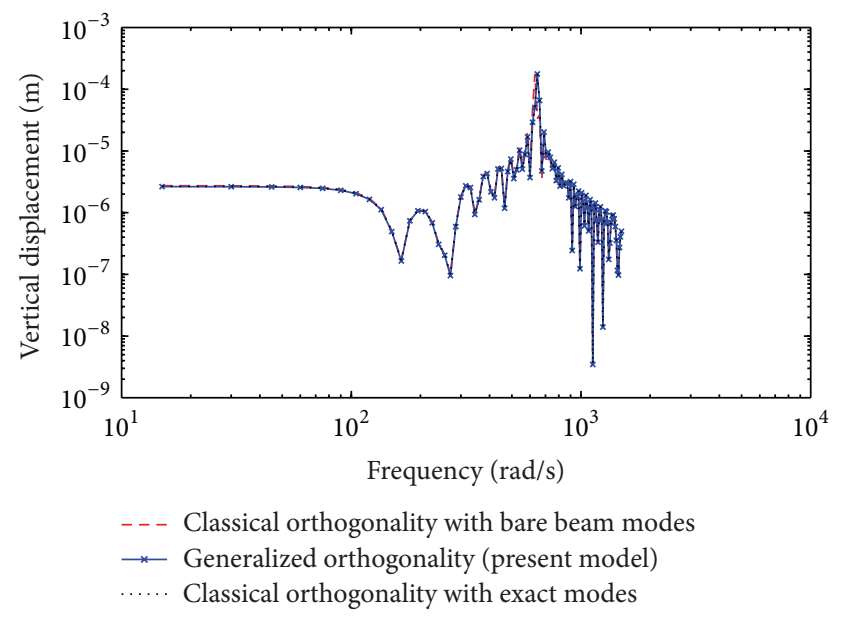

FIGURE 10: Frequency response of a simply supported beam carrying one in-span mass-spring-damper-mass system for $k=190428 \mathrm{~N} / \mathrm{m}$, $M_{d}=3.0775 \mathrm{~kg}, M_{c}=0 \mathrm{~kg}, T=0 \mathrm{~N}, E I=63476.1 \mathrm{Nm}^{2}, c_{d}=$ $100 \mathrm{Ns} / \mathrm{m}$, and $L_{d}=0.75 \mathrm{~m}$.

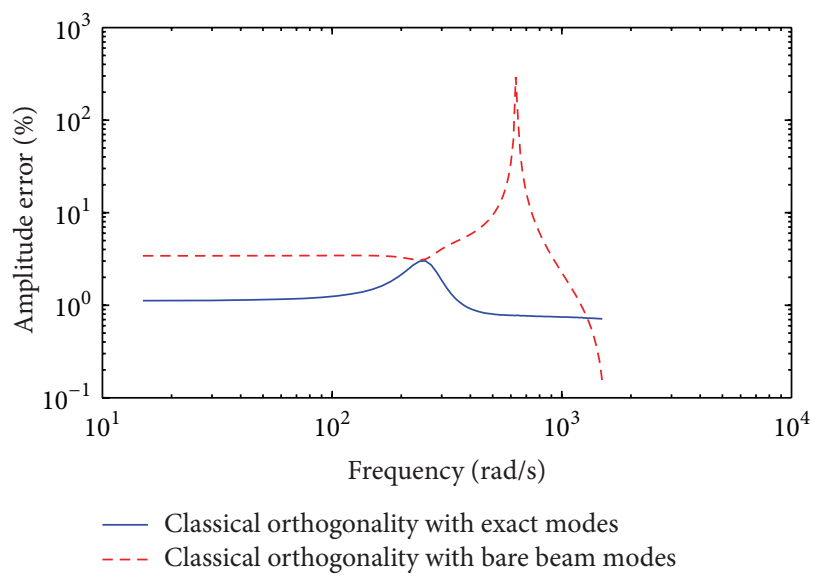

FIGURE 11: Frequency response amplitude error of a simply supported beam carrying one in-span mass-spring-damper-mass system for $k=190428 \mathrm{~N} / \mathrm{m}, M_{d}=3.0775 \mathrm{~kg}, M_{c}=0 \mathrm{~kg}, T=0 \mathrm{~N}$, $E I=63476.1 \mathrm{Nm}^{2}, c_{d}=0.1 \mathrm{Ns} / \mathrm{m}$, and $L_{d}=0.75 \mathrm{~m}$.

orthogonality relations along with the mode shapes of the bare beam. It has been shown, however, that the mode shapes of the bare beam can be quite different from those of the loaded beam. In the present paper, the exact natural frequencies and mode shapes were presented for an axially loaded beam carrying several vibration absorbers. Explicit expressions were presented for the generalized orthogonality condition. The obtained generalized orthogonality relation was employed along with the assumed modes method to study the forced vibrational response. The numerical simulations indicated that using the common approach could produce erroneous results. The combination of the exact mode shapes of the loaded beam and the corresponding generalized orthogonality relation is necessary for accurate dynamic modeling of a beam carrying elastically mounted masses with dampers. 


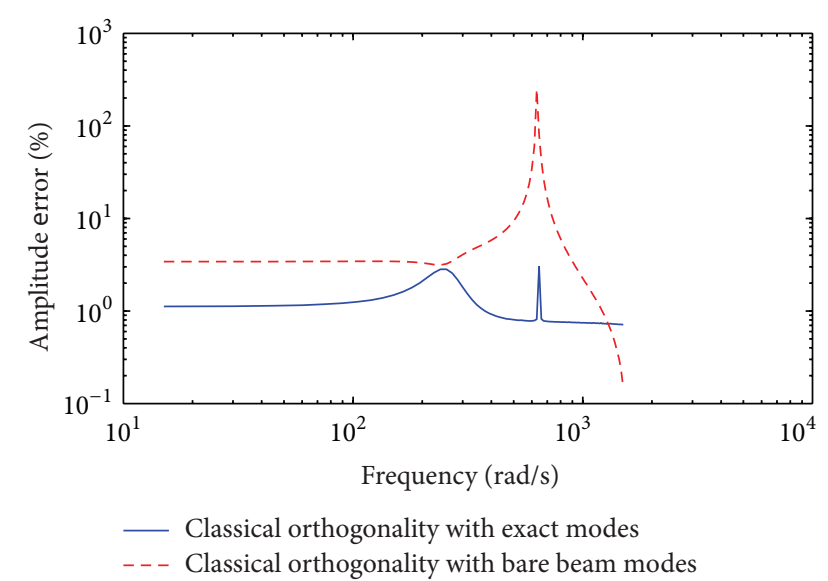

FIGURE 12: Frequency response amplitude error of a simply supported beam carrying one in-span mass-spring-damper-mass system for $k=190428 \mathrm{~N} / \mathrm{m}, M_{d}=3.0775 \mathrm{~kg}, M_{c}=0 \mathrm{~kg}, T=0 \mathrm{~N}$, $E I=63476.1 \mathrm{Nm}^{2}, c_{d}=100 \mathrm{Ns} / \mathrm{m}$, and $L_{d}=0.75 \mathrm{~m}$.

\section{Appendix}

For the sake of simplicity, the following notations are used:

$$
\begin{gathered}
s_{\alpha}=\sin \alpha, \quad c_{\alpha}=\cos \alpha, \\
\operatorname{sh}_{\beta}=\sinh \beta, \quad c h_{\beta}=\cosh \beta, \\
s_{\alpha i}=\sin \alpha\left(\zeta_{i}\right), \quad c_{\alpha i}=\cos \alpha\left(\zeta_{i}\right), \\
\operatorname{sh}_{\beta i}=\sinh \beta\left(\zeta_{i}\right), \quad c h_{\beta i}=\cosh \beta\left(\zeta_{i}\right), \\
\epsilon=K_{1} \gamma_{1}-\eta_{1} .
\end{gathered}
$$

The elements of the matrix $\mathscr{F}$ are expressed as

$$
\begin{aligned}
& \mathscr{F}_{(4 i-1,4 i-3)}=s_{\alpha i}, \quad \mathscr{F}_{(4 i-1,4 i-2)}=c_{\alpha i}, \\
& \mathscr{F}_{(4 i-1,4 i-1)}=s h_{\beta i}, \quad \mathscr{F}_{(4 i-1,4 i)}=c h_{\beta i},
\end{aligned}
$$

$$
\left[\begin{array}{ccc}
0 & 1 & 0 \\
\alpha & 0 & \beta \\
s_{\alpha 1} & c_{\alpha 1} & s h_{\beta 1} \\
\alpha c_{\alpha 1} & -\alpha s_{\alpha 1} & \beta c h_{\beta 1} \\
-\alpha^{2} s_{\alpha 1} & -\alpha^{2} c_{\alpha 1} & \beta^{2} s h_{\beta 1} \\
-\alpha^{3} c_{\alpha 1}+\epsilon s_{\alpha 1} & \alpha^{3} s_{\alpha 1}+\epsilon c_{\alpha 1} & \beta^{3} c h_{\beta 1}+\epsilon s h_{\beta 1} \\
0 & 0 & 0 \\
0 & 0 & 0
\end{array}\right.
$$

\section{Conflict of Interests}

The authors declare that there is no conflict of interests regarding the publication of this paper.

\section{References}

[1] H.-Y. Lin and Y.-C. Tsai, "Free vibration analysis of a uniform multi-span beam carrying multiple spring-mass systems," Journal of Sound and Vibration, vol. 302, no. 3, pp. 442-456, 2007.

$$
\begin{array}{cl}
\mathscr{F}_{(4 i-1,4 i+1)}=-s_{\alpha i}, & \mathscr{F}_{(4 i-1,4 i+2)}=-c_{\alpha i}, \\
\mathscr{F}_{(4 i-1,4 i+3)}=-s h_{\beta i}, & \mathscr{F}_{(4 i-1,4 i+4)}=-c h_{\beta i}, \\
\mathscr{F}_{(4 i, 4 i-3)}=\alpha c_{\alpha i}, & \mathscr{F}_{(4 i, 4 i-2)}=-\alpha s_{\alpha i}, \\
\mathscr{F}_{(4 i, 4 i-1)}=\beta c h_{\beta i}, & \mathscr{F}_{(4 i, 4 i)}=\beta s h_{\beta i}, \\
\mathscr{F}_{(4 i, 4 i+1)}=-\alpha c_{\alpha i}, & \mathscr{F}_{(4 i, 4 i+2)}=\alpha s_{\alpha i}, \\
\mathscr{F}_{(4 i, 4 i+3)}=-\beta c h_{\beta i}, & \mathscr{F}_{(4 i, 4 i+4)}=-\beta s h_{\beta i}, \\
\mathscr{F}_{(4 i+1,4 i-3)}=\alpha^{2} s_{\alpha i}, & \mathscr{F}_{(4 i+1,4 i-2)}=-\alpha^{2} c_{\alpha i}, \\
\mathscr{F}_{(4 i+1,4 i-1)}=\beta^{2} s h_{\beta i}, & \mathscr{F}_{(4 i+1,4 i)}=\beta^{2} c h_{\beta i}, \\
\mathscr{F}_{(4 i+1,4 i+1)}=\alpha^{2} s_{\alpha i}, & \mathscr{F}_{(4 i+1,4 i+2)}=\alpha^{2} c_{\alpha i}, \\
\mathscr{F}_{(4 i+1,4 i+3)}=-\beta^{2} s h_{\beta i}, & \mathscr{F}_{(4 i+1,4 i+4)}=-\beta^{2} c h_{\beta i}, \\
\mathscr{F}_{(4 i+2,4 i-3)}=-\alpha^{3} c_{\alpha i}+\epsilon s_{\alpha i}, & \mathscr{F}_{(4 i+2,4 i-2)}=\alpha^{3} s_{\alpha i}+\epsilon c_{\alpha i}, \\
\mathscr{F}_{(4 i+2,4 i-1)}=\beta^{3} c h_{\beta i}+\epsilon s h_{\beta i}, & \mathscr{F}_{(4 i+2,4 i)}=\beta^{3} s h_{\beta i}+\epsilon c h_{\beta i}, \\
\mathscr{F}_{(4 i+2,4 i+1)}=\alpha^{3} c_{\alpha i}, & \mathscr{F}_{(4 i+2,4 i+2)}=-\alpha^{3} s_{\alpha i}, \\
\mathscr{F}_{(4 i+2,4 i+3)}=-\beta^{3} c h_{\beta i}, & \mathscr{F}_{(4 i+2,4 i+4)}=-\beta^{3} s h_{\beta i} .
\end{array}
$$

$\mathscr{F}_{(1,1)}, \mathscr{F}_{(1,2)}, \mathscr{F}_{(1,3)}, \mathscr{F}_{(1,4)}, \mathscr{F}_{(2,1)}, \mathscr{F}_{(2,2)}, \mathscr{F}_{(2,3)}$, and $\mathscr{F}_{(2,4)}$ depend on the boundary conditions at the origin $x=$ 0 . $\mathscr{F}_{(q-1, p+1)}, \mathscr{F}_{(q-1, p+2)}, \mathscr{F}_{(q-1, p+3)}, \mathscr{F}_{(q-1, p+4)}, \mathscr{F}_{(q, p+1)}$, $\mathscr{F}_{(q, p+2)}, \mathscr{F}_{(q, p+3)}$, and $\mathscr{F}_{(q, p+4)}$ are obtained from the boundary conditions at $x=L$, where $q=4 N+4$ and $p=4 N$.

The frequency equation for a cantilevered beam with one in-span mass-spring-mass support is obtained by taking the determinant of the following matrix:

$$
\left.\begin{array}{ccccc}
1 & 0 & 0 & 0 & 0 \\
0 & 0 & 0 & 0 & 0 \\
c h_{\beta 1} & -s_{\alpha 1} & -c_{\alpha 1} & -s h_{\beta 1} & -c h_{\beta 1} \\
\beta s h_{\beta 1} & -\alpha c_{\alpha 1} & \alpha s_{\alpha 1} & -\beta c h_{\beta 1} & -\beta s h_{\beta 1} \\
\beta^{2} c h_{\beta 1} & \alpha^{2} s_{\alpha 1} & \alpha^{2} c_{\alpha 1} & -\beta^{2} s h_{\beta 1} & -\beta^{2} c h_{\beta 1} \\
s h_{\beta 1}+\epsilon c h_{\beta 1} & \alpha^{3} c_{\alpha 1} & -\alpha^{3} s_{\alpha 1} & -\beta^{3} c h_{\beta 1} & -\beta^{3} s h_{\beta 1} \\
0 & s_{\alpha} & c_{\alpha} & s h_{\beta} & c h_{\beta} \\
0 & \alpha c_{\alpha} & -\alpha s_{\alpha} & \beta c h_{\beta} & \beta s h_{\beta}
\end{array}\right] .
$$

[2] P. A. Hassanpour, W. L. Cleghorn, J. K. Mills, and E. Esmailzadeh, "Exact solution of the oscillatory behavior under axial force of a beam with a concentrated mass within its interval," Journal of Vibration and Control, vol. 13, no. 12, pp. 1723-1739, 2007.

[3] G. Şakar, "The effect of axial force on the free vibration of an Euler-Bernoulli beam carrying a number of various concentrated elements," Shock and Vibration, vol. 20, no. 3, pp. 357-367, 2013. 
[4] H. Xiao, M. Sheng, Z. Liu, and Z. Wei, "The study on free vibration of elastically restrained beams carrying various types of attachments with arbitrary spatial distributions," Shock and Vibration, vol. 20, no. 3, pp. 369-383, 2013.

[5] H. Su and J. R. Banerjee, "Exact natural frequencies of structures consisting of two-part beam-mass systems," Structural Engineering and Mechanics, vol. 19, no. 5, pp. 551-566, 2005.

[6] K. Saeedi and R. B. Bhat, "Clustered natural frequencies in multi-span beams with constrained characteristic functions," Shock and Vibration, vol. 18, no. 5, pp. 697-707, 2011.

[7] Y. Yesilce, "Free vibrations of a Reddy-Bickford multi-span beam carrying multiple spring-mass systems," Shock and Vibration, vol. 18, no. 5, pp. 709-726, 2011.

[8] Y. Chen, "On the vibration of a beam or rods carrying a concentrated mass," Journal of Applied Mechanics, vol. 30, no. 2, pp. 310-311, 1963.

[9] S. Naguleswaran, "Transverse vibrations of an Euler-Bernoulli uniform beam carrying two particles in-span," International Journal of Mechanical Sciences, vol. 43, no. 12, pp. 2737-2752, 2001.

[10] J.-S. Wu and T.-L. Lin, "Free vibration analysis of a uniform cantilever beam with point masses by an analytical-and-numericalcombined method," Journal of Sound and Vibration, vol. 136, no. 2, pp. 201-213, 1990.

[11] M. Gürgöze, "On the alternative formulations of the frequency equation of a Bernoulli-Euler beam to which several springmass systems are attached in-span," Journal of Sound and Vibration, vol. 217, no. 3, pp. 585-595, 1998.

[12] P. D. Cha, "Natural frequencies of a linear elastica carrying any number of sprung masses," Journal of Sound and Vibration, vol. 247, no. 1, pp. 185-194, 2001.

[13] O. R. Barry, J. Zu, J. W. Zu, and D. C. D. Oguamanam, "Free vibration analysis of a beam under axial load carrying a massspring-mass system," in Proceedings of the ASME International Design Engineering Technical Conferences \& Computers and Information in Engineering Conference (IDETC/CIE '12), pp. 791-796, Chicago, Ill, USA, August 2012.

[14] M. N. Hamdan and B. A. Jubran, "Free and forced vibrations of a restrained cantilever beam carrying a concentrated mass," Journal of Engineering Science, vol. 3, no. 1, pp. 71-83, 1991.

[15] F. S. Samani and F. Pellicano, "Vibration reduction on beams subjected to moving loads using linear and nonlinear dynamic absorbers," Journal of Sound and Vibration, vol. 325, no. 4-5, pp. 742-754, 2009.

[16] J.-S. Wu and D.-W. Chen, "Dynamic analysis of a uniform cantilever beam carrying a number of elastically mounted point masses with dampers," Journal of Sound and Vibration, vol. 229, no. 3, pp. 549-578, 2000.

[17] J.-S. Wu and C.-G. Huang, "Free and forced vibrations of a Timoshenko beam with any number of translational and rotational springs and lumped masses," Communications in Numerical Methods in Engineering, vol. 11, no. 9, pp. 743-756, 1995.

[18] B. Zhang and S. Shepard, "Dynamic response of supported beams with intermediate supports under moving loads," Shock and Vibration, vol. 19, no. 6, pp. 1403-1413, 2012.

[19] T.-P. Chang and C.-Y. Chang, "Vibration analysis of beams with a two degree-of-freedom spring-mass system," International Journal of Solids and Structures, vol. 35, no. 5-6, pp. 383-401, 1998.

[20] K. H. Low, "Comments on "non-linear vibrations of a beammass system under different boundary conditions" (with authors' reply)," Journal of Sound and Vibration, vol. 207, no. 2, pp. 284-287, 1997.

[21] E. Özkaya and M. Pakdemirli, "Non-linear vibrations of a beammass system with both ends clamped," Journal of Sound and Vibration, vol. 221, no. 3, pp. 491-503, 1999.

[22] M. H. Ghayesh, F. Alijani, and M. A. Darabi, "An analytical solution for nonlinear dynamics of a viscoelastic beam-heavy mass system," Journal of Mechanical Science and Technology, vol. 25, no. 8, pp. 1915-1923, 2011.

[23] M. H. Ghayesh, S. Kazemirad, and M. A. Darabi, "A general solution procedure for vibrations of systems with cubic nonlinearities and nonlinear/time-dependent internal boundary conditions," Journal of Sound and Vibration, vol. 330, no. 22, pp. 5382-5400, 2011.

[24] C. L. Kirk and S. M. Wiedemann, "Natural frequencies and mode shapes of a free-free beam with large end masses," Journal of Sound and Vibration, vol. 254, no. 5, pp. 939-949, 2002.

[25] P. A. Hassanpour, E. Esmailzadeh, W. L. Cleghorn, and J. K. Mills, "Generalized orthogonality condition for beams with intermediate lumped masses subjected to axial force," Journal of Vibration and Control, vol. 16, no. 5, pp. 665-683, 2010. 

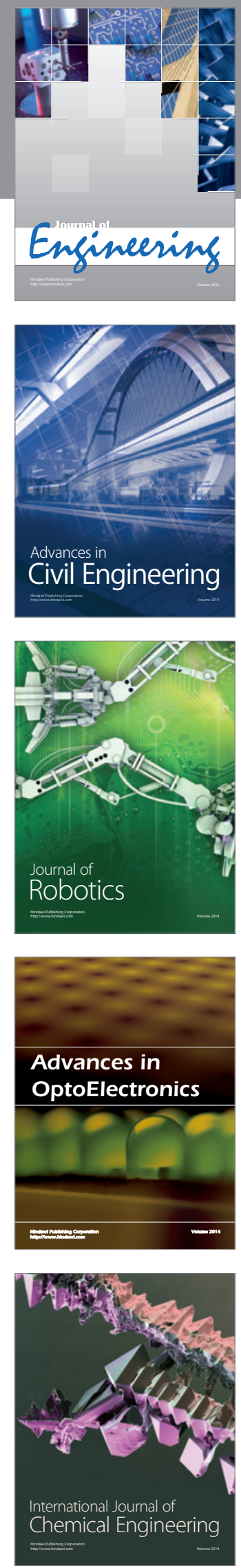

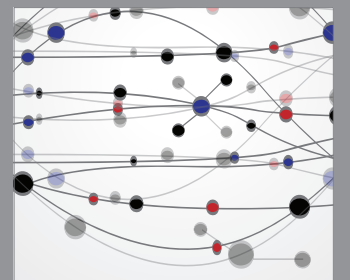

The Scientific World Journal
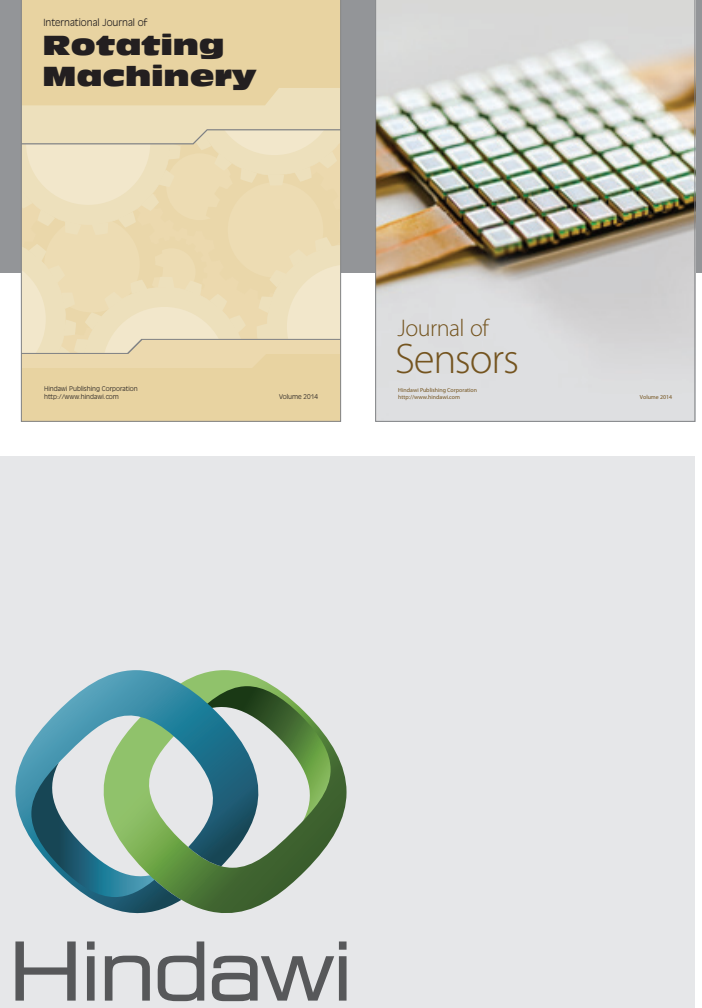

Submit your manuscripts at http://www.hindawi.com
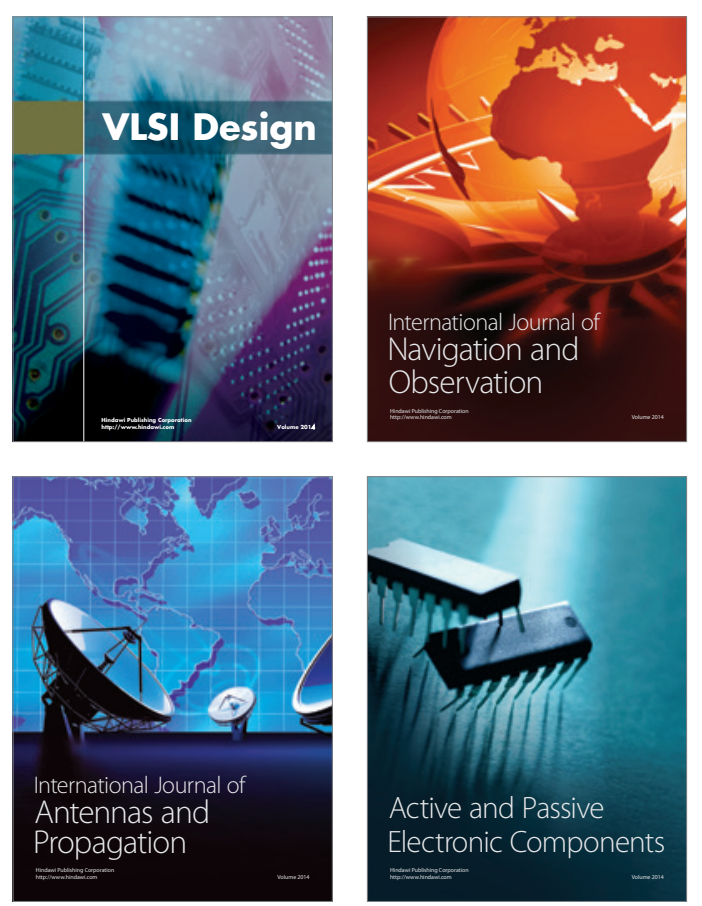
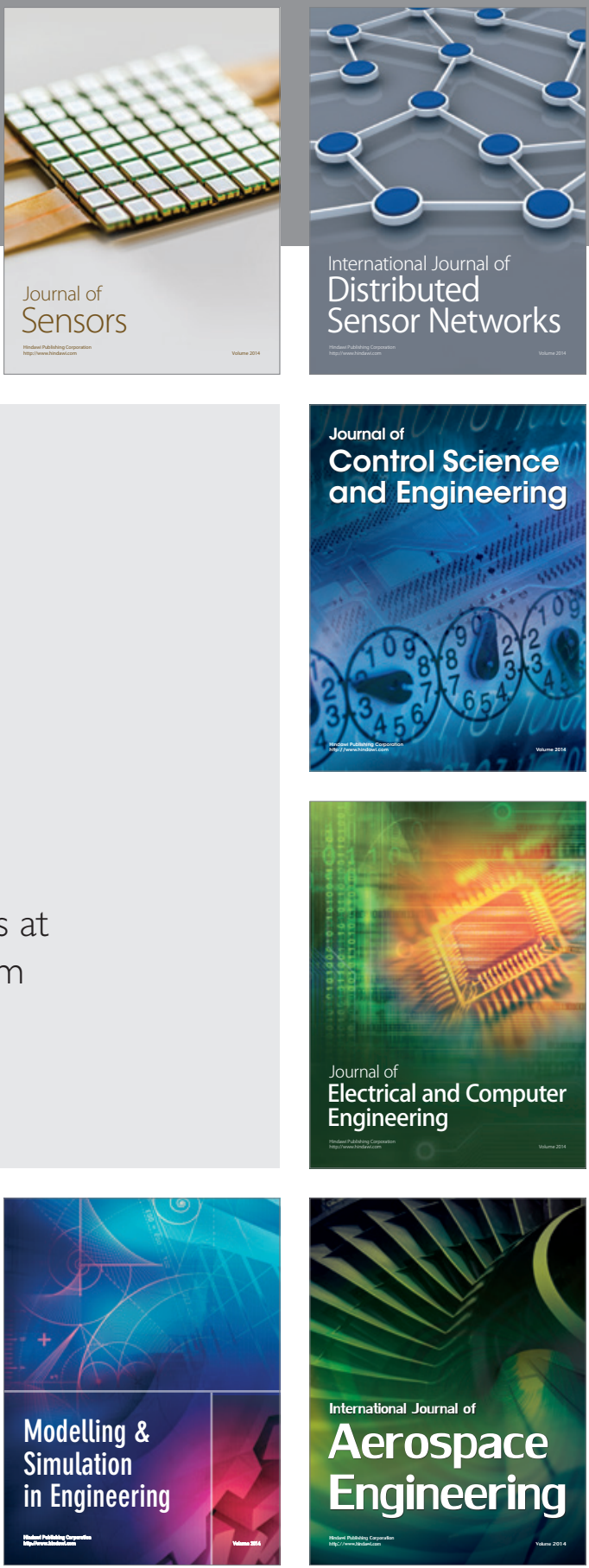

Journal of

Control Science

and Engineering
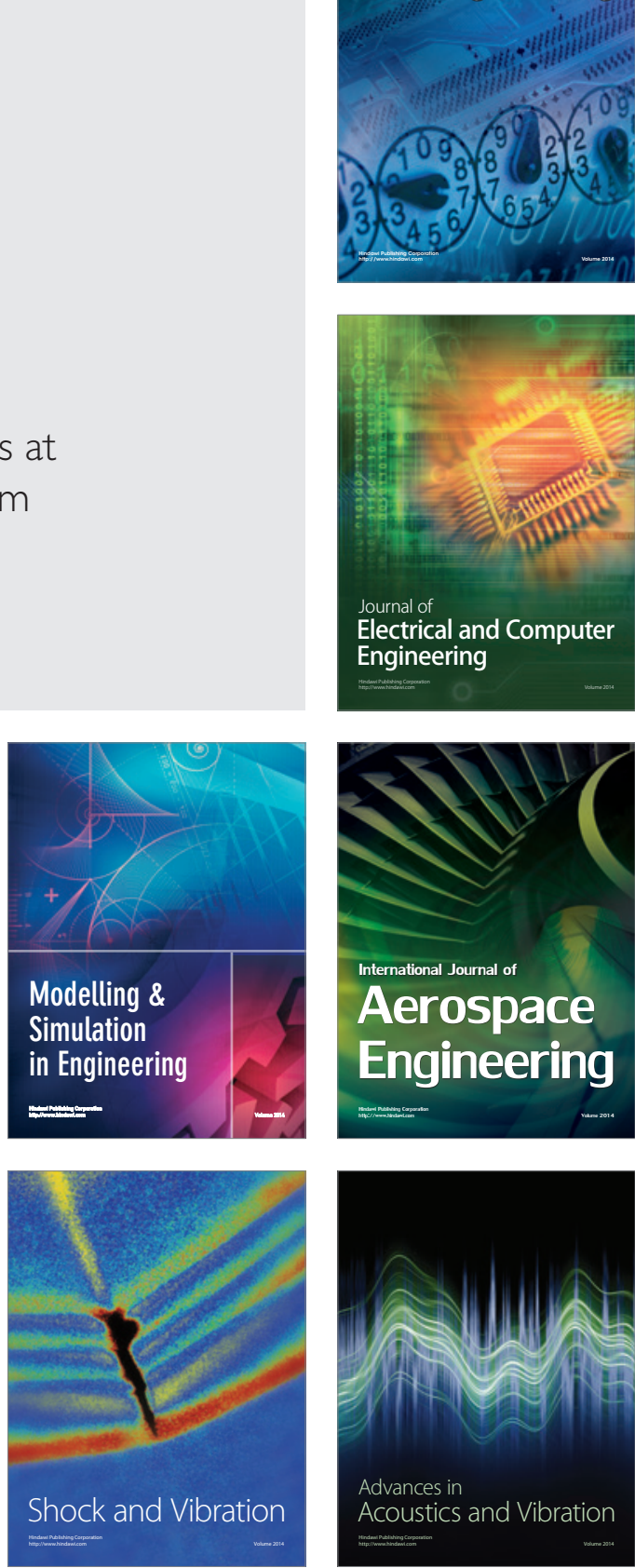